\title{
Is There Any Room for Pharmacometrics With Immuno-Oncology Drugs? Input from the EORTC-PAMM Course on Preclinical and Early-phase Clinical Pharmacology
}

\author{
ANNE RODALLEC ${ }^{1,2}$, RAPHAELLE FANCIULLINO ${ }^{1,2}$, \\ SEBASTIEN BENZEKRY ${ }^{2,3}$ and JOSEPH CICCOLINI ${ }^{1,2}$ on Behalf of the EORTC PAMM Group \\ ${ }^{1}$ SMARTc Unit, CRCM, Inserm UMR1068, CNRS UMR7258, Aix-Marseille University, Marseille, France; \\ ${ }^{2}$ Pharmacology \& Molecular Mechanisms (PAMM) Group, \\ European Organization for Research and Treatment on Cancer (EORTC), Brussels, Belgium; \\ ${ }^{3}$ MONC Team, INRIA, Bordeaux, France
}

\begin{abstract}
As part of the Pharmacology \& Molecular Mechanisms (PAMM) Group, European Organization for Research and Treatment on Cancer (EORTC) 2019 winter Meeting Educational sessions, special focus has been placed on strategies to be undertaken to reduce the attrition rate when developing immune-oncology drugs. Immune checkpoint inhibitors have been game-changing drugs in several settings over the past decade such as melanoma and lung cancer. However, during the last years a rising number of studies failing to further improve clinical outcome in patients with cancer was recorded. Extensive pharmacometrics such as pharmacokinetics/ pharmacodynamics modeling support should help to overcome the current glass ceiling that has apparently been reached with immuno-oncology drugs (IOD). In particular, it should help in the issue of setting up combinatorial regimen (i.e. combining immune checkpoint inhibitors with cytotoxics, anti-angiogenesis or targeted therapies) that can no longer be addressed when following standard trial-and-error approaches, but rather by using mathematical-derived algorithms as decision-making tools by investigators for rational design. In routine clinical setting, developing therapeutic drug monitoring of immune checkpoint inhibitors with adaptive dosing strategies has been a longneglected strategy. Still, substantial improvements might be achieved using dedicated tools for precision medicine and personalized medicine in immunotherapy.
\end{abstract}

Correspondence to: Dr. Joseph Ciccolini, SMARTc Unit CRCM Faculty of Pharmacy of Marseille, 27 Vd Jean Moulin 13385, Marseille 05, France. Tel: +33 491835509, e-mail: joseph.ciccolini@univ-amu.fr

Key Words: Immuno-oncology drugs, PK/PD, pharmacometrics, combinatorial strategies, review.
The rise of immunotherapy has fueled huge hope among oncologists, researchers and the patient community as patients with malignant diseases with a once dismal prognosis have now reached 3-year survival of 20-30\% (1). However, the efficacy of anti-cytotoxic T-lymphocyte antigen 4 (CTLA4) and drugs interfering with the programmed cell death receptor 1 (PD1) and programmed cell death ligand 1 (PDL1) axis remains limited to a small subset of patients with an even more limited small subset of tumors such as metastatic melanoma and non-small cell lung cancer. In the majority of patients, disease fails to respond to immune checkpoint inhibitors (2). To help increase both response rates and eventually extend survival, combinatorial strategies, i.e. by associating immune checkpoint inhibitors with drugs likely to harnessing tumor immunity, are now seen as the future of oncology. Targeted therapies, cytotoxics, anti-angiogenic drugs and radiation therapy are all expected to turn immunologically 'cold' tumors into 'hot' tumors, e.g. by triggering immunogenic cell death or by affecting the tumor micro-environment. For instance, combining anti-PDL1 atezolizumab with nab-paclitaxel nano-conjugated drug led to marked improvement of clinical outcome in patients with triple-negative breast cancer (3), much probably because of the wide range of immunomodulatory properties nanoparticles display (4). However, as for single-agent immunotherapy, many recent attempts based upon multi-drug association have not managed to yield convincing results. For instance, combining anti-indoleamine 2,3-dioxygenase (IDO) epacadostat with anti-PD1 pembrolizumab failed to improve clinical outcome of patients with lung cancer in phase III trial despite promising phase I and II studies (5). Similarly, attempts to combine atezolizumab with 5-fluorouracil and vascular 
endothelial growth factor A bevacizumab in patients with colorectal cancer had to be stopped because of lack of efficacy (6). Elsewhere, combinatorial strategies between anti-PD1 and radiation therapy based upon expected abscopal effects were similarly disappointing (7). For these negative studies, a commonality is the apparent lack of rationale when setting up the combination as all treatments were given concomitantly, regardless of any sequencing effect, plus a complete lack of pharmacokinetic support that could help in checking that required plasma drug levels are reached in patients.

\section{When Trial-and-Error Practices Are No Longer Suitable}

Harnessing tumor immunity with standard treatments is an appealing strategy. However, defining the exact dosing, scheduling and sequencing of each respective drug to be associated with immune checkpoint inhibitors is a complicated, yet largely underestimated when not merely ignored task. For instance, cytotoxics can act as immunomodulatory agents though a wide variety of actions, ranging from triggering immunogenic cell death to reengineering the tumor micro-environment or modulating the 'gas' (activated T-lymphocytes, dendritic cells, antigenpresenting cells) and 'brake' (regulatory T-cells, myeloidderived suppressive cells (MDSCs) pedals. Of note, the primary action of cytotoxics seems to be drug-, dose- and schedule-dependent. For instance, standard chemotherapy is expected to increase expression of neoantigens and to boost infiltration of T-lymphocytes, whereas metronomic chemotherapy might have action specifically directed towards regulatory T-cells and MDSCs (8). Consequently, extensive efforts to understand the optimal modality of drug administration are necessary prior to setting up a combination with IOD. For instance, with oral targeted therapies it has been demonstrated that slight changes in scheduling between anti-CD4/6 and anti-PDL1 was sufficient to lead to marked changes in antitumor efficacy in mice, highlighting how the combination required fine tuning (9). The situation is even trickier when considering that, in theory, for combinatorial strategies requiring more than two drugs to be associated, testing all the sequences possible between one cytotoxic, one targeted therapy, one antiangiogenic, and one immune checkpoint inhibitor plus radiation therapy would require a 120-arm comparative study. Because such a requirement is not achievable, developing in-silico tools to investigate the countless combination between drugs, doses, schedule and sequences seems to be the best way to determine at low cost the best modality of association prior to starting the actual clinical investigations (10). For instance, several models have been published to test in-silico metronomic regimens so as to define the best combination between dosing, frequency and treatment duration $(11,12)$. After validation in an animal model (13), the mathematical algorithm was used to drive a phase I/II clinical trial in patients with lung cancer (14). Using such model-informed dosing might help to better combine metronomic chemotherapy with immune checkpoint inhibitors, as empirical attempts such as low-dose cyclophosphamide/prembrolizumab for patients with sarcoma, have failed to produce convincing results (15).

\section{Are Pharmacokinetic/Pharmacodynamic (PK/PD) Relationships the Missing Biomarker with Immunotherapy?}

IOD are all monoclonal antibodies displaying specific behavior in the body (16). For a long time, PK/PD relationships for biologics were largely ignored, until a rising number of clinical reports demonstrated that exposure levels (mostly through concentrations in plasma) with trastuzumab (anti-human epidermal receptor) (17), cetuximab (antiepidermal growth factor receptor) (18), rituximab (antiCD20) (19), and bevacizumab (anti-vascular endothelial growth factor) (20) were associated with response or survival. Actually, it seems that ensuring a sustained $80 \%$ targeted engagement is necessary to achieve clinical efficacy, i.e. antibodies must always remain above a certain threshold of plasma concentration to inhibit the target. With immune checkpoint inhibitors, similar exposure-effect relationships have been demonstrated with anti-CTLA4 ipilimumab, and residual concentrations were found to be associated with both survival and toxicity in patients with metastatic melanoma. Similar association between exposure levels and clinical outcome was evidenced with anti-PDL1 avelumab (21). With anti-PD1 nivolumab, it was first proposed that PK/PD relationships were flat because low doses (i.e. much lower than approved dosing) were sufficient to inhibit $>70 \%$ of PD1; however, this was shown by measuring PD1 engagement in circulating T-lymphocytes, and not at the tumor level as expected (22). Therefore, the actual PK/PD relationships with nivolumab at the tumor site remain unknown. Of note, a recent clinical study showed that trough levels of nivolumab were associated with response in patients with non-small cell lung cancers, thus suggesting that pharmacokinetics might be a critical parameter when predicting clinical outcome (23). Overall and although clinical reports are sparse, this calls for implementing therapeutic drug monitoring strategies with IOD so as to check whether exposure levels ensuring a good probability of response are reached in patients, as causes for inter-individual variability remain largely unknown for use of biologics (24). Should patients be inadequately exposed, adaptive dosing (i.e. using Bayesian-based procedures and population approaches) should be undertaken to correct exposure. 


\section{Conclusion}

The era of immunotherapy has fueled huge expectations that remain partially unfulfilled because only a minority of patients have long-term benefit of the use of immune checkpoint inhibitors. Pharmacometrics might partly help to improve current clinical outcomes through a better definition of combinatorial strategies and development or adaptive dosing if required.

\section{Conflicts of Interest}

The Authors have no conflicts of interest to declare in relation with the content of this article.

\section{Authors' Contributions}

Anne Rodallec, Sebastien Benzekry and Joseph Ciccolini collected published data and available material in preparation of the article. Anne Rodallec, Raphaelle Fanciullino, Sebastien Benzekry and Joseph Ciccolini structured, wrote and approved the article.

\section{Acknowledgements}

The Authors would like to thank the Organizing Committee of the EORTC-PAMM winter meeting. Items treated in this article were key points approached during the Educational Course on "Preclinical Pharmacology and Early-phase Clinical Pharmacology" 2019, Verona, Italy.

\section{References}

1 Marin-Acevedo JA, Dholaria B, Soyano AE, Knutson KL, Chumsri S and Lou Y: Next generation of immune checkpoint therapy in cancer: New developments and challenges. J Hematol Oncol 11: 39, 2018. PMID: 29544515. DOI: 10.1186/s13045018-0582-8

2 Whiteside TL, Demaria S, Rodriguez-Ruiz ME, Zarour HM and Melero I: Emerging opportunities and challenges in cancer immunotherapy. Clin Cancer Res 22: 1845-1855, 2016. PMID: 27084738. DOI: 10.1158/1078-0432.CCR-16-0049

3 Schmid P, Adams S, Rugo HS, Schneeweiss A, Barrios CH, Iwata H, Diéras V, Hegg R, Im S-A, Shaw Wright G, Henschel V, Molinero L, Chui SY, Funke R, Husain A, Winer EP, Loi S, Emens LA and IMpassion130 Trial Investigators: Atezolizumab and nab-paclitaxel in advanced triple-negative breast cancer. N Engl J Med 379: 2108-2121, 2018. PMID: 30345906. DOI: 10.1056/NEJMoa1809615

4 Rodallec A, Sicard G, Fanciullino R, Benzekry S, Lacarelle B, Milano $\mathrm{G}$ and Ciccolini J: Turning cold tumors into hot tumors: Harnessing the potential of tumor immunity using nanoparticles. Expert Opin Drug Metab Toxicol 11: 1139-11475, 2018. PMID: 30354685. DOI: $10.1080 / 17425255.2018 .1540588$

5 Long GV, Dummer R, Hamid O, Gajewski T, Caglevic C, Dalle S, Arance A, Carlino MS, Grob J-J, Kim TM, Demidov LV, Robert C, Larkin JMG, Anderson J, Maleski JE, Jones MM, Diede SJ and Mitchell TC: Epacadostat (E) plus pembrolizumab (P) versus pembrolizumab alone in patients (pts) with unresectable or metastatic melanoma: Results of the phase 3 ECHO-301/KEYNOTE-252 study. J Clin Oncol 36: 108-108, 2018. PMID: 28891423. DOI: 10.1056/NEJMoa1709030

6 Grothey A, Tabernero J, Arnold D, De Gramont A, Ducreux MP, O'Dwyer PJ, van Cutsem E, Bosanac I, Srock S, Mancao C, Gilberg F, Winter $\mathrm{J}$ and Schmoll H: Fluoropyrimidine and bevacizumab plus or minus atezolizumab as first-line treatment for $B R A F$ wild-type metastatic colorectal cancer: Findings from the MODUL trial of biomarker-driven maintenance. ESMO 2018 Congress, abstract LBA19, 2018.

7 McBride SM, Sherman EJ, Tsai CJ, Baxi SS, Aghalar J, Eng J, Zhi WI, McFarland DC, Michel LS, Spielsinger D, Zhang Z, Flynn J, Dunn L, Ho AL, Riaz N, Pfister DG and Lee NY: A phase II randomized trial of nivolumab with stereotactic body radiotherapy (SBRT) versus nivolumab alone in metastatic (M1) head and neck squamous cell carcinoma (HNSCC). J Clin Oncol 15_suppl: 6009-6009, 2018. DOI: 10.1200/JCO.2018. 36.15_ supp1.6009

8 Kepp O, Galluzzi L, Martins I, Schlemmer F, Adjemian S, Michaud M, Sukkurwala AQ, Menger L, Zitvogel L and Kroemer G: Molecular determinants of immunogenic cell death elicited by anticancer chemotherapy. Cancer Metastasis Rev 30: 61-69, 2011. PMID: 21249425. DOI: 10.1007/s 10555-011-9273-4

9 Schaer DA, Beckmann RP, Dempsey JA, Huber L, Forest A, Amaladas N, Li Y, Wang YC, Rasmussen ER, Chin D, Capen A, Carpenito C, Staschke KA, Chung LA, Litchfield LM, Merzoug FF, Gong X, Iversen PW, Buchanan S, de Dios A, Novosiadly RD and Kalos M: The CDK4/6 inhibitor abemaciclib induces a T-cell inflamed tumor microenvironment and enhances the efficacy of PD-L1 checkpoint blockade. Cell Rep 22: 29782994, 2018. PMID: 29539425. DOI: 10.1016/j.celrep

10 Barbolosi D, Ciccolini J, Lacarelle B, Barlési F and André N: Computational oncology--mathematical modelling of drug regimens for precision medicine. Nat Rev Clin Oncol 13: 242254, 2016. PMID: 26598946. DOI: 10.1038/nrclinonc. 2015.204

11 Barbolosi D, Ciccolini J, Meille C, Elharrar X, Faivre C, Lacarelle $\mathrm{B}$, André $\mathrm{N}$ and Barlesi F: Metronomics chemotherapy: time for computational decision support. Cancer Chemother Pharmacol 74: 647-652, 2014. PMID: 25082520. DOI: 10.1007/s00280-0142546-1

12 Benzekry S, Pasquier E, Barbolosi D, Lacarelle B, Barlési F, André $\mathrm{N}$ and Ciccolini J: Metronomic reloaded: Theoretical models bringing chemotherapy into the era of precision medicine. Semin Cancer Biol 35: 53-61, 2015. PMID: 26361213. DOI: 10.1016/j.semcancer.2015.09.002

13 Ciccolini J, Barbolosi D, Meille C, Lombard A, Serdjebi C, Giacometti S, Padovani L, Pasquier E and André N: Pharmacokinetics and pharmacodynamics-based mathematical modeling identifies an optimal protocol for metronomic chemotherapy. Cancer Res 77: 4723-4733, 2017. PMID: 28655786. DOI: 10.1158/0008-5472.CAN-16-3130

14 Barlesi F, Imbs D-C, Tomasini P, Greillier L, Galloux M, TestotFerry A, Garcia M, Elharrar X, Pelletier A, André N, Mascaux C, Lacarelle B, Cheikh RE, Serre R, Ciccolini J and Barbolosi D: Mathematical modeling for phase I cancer trials: A study of metronomic vinorelbine for advanced non-small cell lung cancer (NSCLC) and mesothelioma patients. Oncotarget 8: 4716147166, 2017. PMID: 28525370. DOI: 10.18632/oncotarget. 17562 
15 Toulmonde M, Penel N, Adam J, Chevreau C, Blay J-Y, Le Cesne A, Bompas E, Piperno-Neumann S, Cousin S, Grellety T, Ryckewaert T, Bessede A, Ghiringhelli F, Pulido M and Italiano A: Use of PD-1 targeting, macrophage infiltration, and IDO pathway activation in sarcomas: A phase 2 clinical trial. JAMA Oncol 4: 93-97, 2018. PMID: 28662235. DOI: 10.1001/ jamaoncol.2017.1617

16 Centanni M, Moes DJAR, Trocóniz IF, Ciccolini J and van Hasselt JGC: Clinical pharmacokinetics and pharmacodynamics of immune checkpoint inhibitors. Clin Pharmacokinet, 2019. PMID: 30815848. DOI: 10.1007/s40262-019-00748-2

17 Cosson VF, Ng VW, Lehle $\mathrm{M}$ and Lum BL: Population pharmacokinetics and exposure-response analyses of trastuzumab in patients with advanced gastric or gastroesophageal junction cancer. Cancer Chemother Pharmacol 73: 737-747, 2014. PMID: 24519752. DOI: 10.1007/s00280-014-2400-5

18 Becher F, Ciccolini J, Imbs D-C, Marin C, Fournel C, Dupuis C, Fakhry N, Pourroy B, Ghettas A, Pruvost A, Junot C, Duffaud F, Lacarelle B and Salas S: A simple and rapid LC-MS/MS method for therapeutic drug monitoring of cetuximab: a GPCOUNICANCER proof of concept study in head-and-neck cancer patients. Sci Rep 7: 2714, 2017. PMID: 28578404. DOI: 10.1038/s41598-017-02821-x

19 Tout M, Casasnovas O, Meignan M, Lamy T, Morschhauser F, Salles G, Gyan E, Haioun C, Mercier M, Feugier P, Boussetta S, Paintaud G, Ternant D and Cartron G: Rituximab exposure is influenced by baseline metabolic tumor volume and predicts outcome of DLBCL patients: A Lymphoma Study Association report. Blood 129: 2616-2623, 2017. PMID: 28251914. DOI: 10.1182/blood-2016-10-744292

20 Caulet M, Lecomte T, Bouché O, Rollin J, Gouilleux-Gruart V, Azzopardi N, Léger J, Borg C, Douillard J-Y, Manfredi S, Smith D, Capitain O, Ferru A, Moussata D, Terrebone E, Paintaud G and Ternant D: Bevacizumab pharmacokinetics influence overall and progression-free survival in metastatic colorectal cancer patients. Clin Pharmacokinet 55: 1381-1394, 2016. PMID: 27312193. DOI: $10.1007 / \mathrm{s} 40262-016-0406-3$
21 Heery CR, O'Sullivan-Coyne G, Madan RA, Cordes L, Rajan A, Rauckhorst M, Lamping E, Oyelakin I, Marté JL, Lepone LM, Donahue RN, Grenga I, Cuillerot J-M, Neuteboom B, Heydebreck A von, Chin K, Schlom J and Gulley JL: Avelumab for metastatic or locally advanced previously treated solid tumours (JAVELIN Solid Tumor): A phase 1a, multicohort, dose-escalation trial. Lancet Oncol 18: 587-598, 2017. PMID: 28373007. DOI: 10.1016/S1470-2045(17)30239-5

22 Topalian SL, Hodi FS, Brahmer JR, Gettinger SN, Smith DC, McDermott DF, Powderly JD, Carvajal RD, Sosman JA, Atkins MB, Leming PD, Spigel DR, Antonia SJ, Horn L, Drake CG, Pardoll DM, Chen L, Sharfman WH, Anders RA, Taube JM, McMiller TL, Xu H, Korman AJ, Jure-Kunkel M, Agrawal S, McDonald D, Kollia GD, Gupta A, Wigginton JM and Sznol M: Safety, activity, and immune correlates of anti-PD-1 antibody in cancer. N Engl J Med 366: 2443-2454, 2012. PMID: 22658127. DOI: $10.1056 /$ NEJMoa1200690

23 Basak EA, Koolen SLW, Hurkmans DP, Schreurs MWJ, Bins S, Oomen-de Hoop E, Wijkhuijs AJM, Besten I den, Sleijfer S, Debets R, van der Veldt AAM, Aerts JGJV and Mathijssen RHJ: Correlation between nivolumab exposure and treatment outcomes in non-small-cell lung cancer. Eur J Cancer 109: 1220, 2019. PMID: 30654225. DOI: 10.1016/j.ejca.2018.12.008

24 Keizer RJ, Huitema ADR, Schellens JHM and Beijnen JH: Clinical pharmacokinetics of therapeutic monoclonal antibodies. Clin Pharmacokinet 49: 493-507, 2010. PMID: 20608753. DOI: $10.2165 / 11531280-000000000-00000$
Received May 15, 2019

Revised June 7, 2019

Accepted June 18, 2019 